\title{
A population-based study of the stratum corneum moisture
}

This article was published in the following Dove Press journal:

Clinical, Cosmetic and Investigational Dermatology

18 April 2016

Number of times this article has been viewed

\section{Thiago de Farias Pires' \\ Ana Paula Azambuja ${ }^{2}$ \\ Andrea Roseli Vançan \\ Russo Horimoto' \\ Mary Sanae Nakamura ${ }^{2}$ \\ Rafael de Oliveira Alvim' \\ José Eduardo Krieger' \\ Alexandre Costa Pereira' \\ 'Laboratory of Genetics and Molecular Cardiology, Heart Institute, University of São Paulo Medical School, ${ }^{2}$ Natura Innovation and Product Technology Ltd., Cajamar, SP, Brazil}

Correspondence:Thiago de Farias Pires; Alexandre Costa Pereira

Laboratory of Genetics and Molecular Cardiology, Heart Institute, University of São Paulo Medical School, Avenida Doutor Enéas de Carvalho Aguiar, 44, São Paulo, SP 05403-900, Brazi Tel +55 I I 266 | 5993

Email thiagofp@usp.br; alexandre. pereira@incor.usp.br
Background: The stratum corneum (SC) has important functions as a bound-water modulator and a primary barrier of the human skin from the external environment. However, no large epidemiological study has quantified the relative importance of different exposures with regard to these functional properties. In this study, we have studied a large sample of individuals from the Brazilian population in order to understand the different relationships between the properties of SC and a number of demographic and self-perceived variables.

Methods: One thousand three hundred and thirty-nine individuals from a rural Brazilian population, who were participants of a family-based study, were submitted to a cross-sectional examination of the SC moisture by capacitance using the Corneometer ${ }^{\circledR}$ CM820 and investigated regarding environmental exposures, cosmetic use, and other physiological and epidemiological measurements. Self-perception-scaled questions about skin conditions were also applied.

Results: We found significant associations between SC moisture and sex, age, high sun exposure, and sunscreen use frequency $(P<0.025)$. In specific studied sites, self-reported race and obesity were also found to show significant effects. Dry skin self-perception was also found to be highly correlated with the objective measurement of the skin. Other environmental effects on SC moisture are also reported.

Keywords: investigative dermatology, stratum corneum moisture, Corneometer, sun exposure, familial data modeling

\section{Introduction}

Formed mainly by corneocytes surrounded by a very organized insoluble lipid envelope ${ }^{1}$ and low-molecular-weight molecules responsible for moisture properties (the natural moisturizing factor), ${ }^{2}$ the stratum corneum (SC), the outermost layer of the skin, is responsible for both water retention and the permeability barrier of the skin, serving as a bound-water modulator ${ }^{3}$ and also as a primary barrier of the body for pathogens, toxic components, and part of the radiation striking the organ. ${ }^{4}$ Previous studies have reported that the characteristics of the human SC show several variations according to the body region, ${ }^{5}$ sex, and also the external and internal temperatures. ${ }^{6}$ Changes on this layer have been correlated with several topical pathologies of the skin, such as psoriasis, ${ }^{7}$ dermatitis, ${ }^{8}$ and other (including genetic) disorders. ${ }^{9}$

The search for new methods that avoid the use of animal testing in experiments has brought new noninvasive devices for in vivo measurements of the human skin. Several devices are commercially available for the measurement of the moisture of the SC using different approaches, including biochemical, electrical, chemical, and imaging methods. ${ }^{10}$ 
One of these is the Corneometer ${ }^{\circledR}$ CM820 (Courage + Khazaka Electronic, Cologne, Germany), which uses the capacitance principle to measure the water content of the SC. ${ }^{11,12}$

Factors that modify the moisture of the SC are not completely explained in the literature. However, it is known that environmental exposure, individual habits, and several extrinsic and intrinsic factors can modify the state of the layer and its expected behavior. ${ }^{13}$ This knowledge is of great importance to the cosmetic industry for the development of products that take into account intrinsic and extrinsic variations of the organ, in the explanation of causal effects that act upon the skin, in the full comprehension of skin pathologies, and in the improvement of topically administered drug. Yet, the relative proportion of contribution due to each factor is not well described, which can lead to inaccurate experiments or treatments. In order to measure these quantities, a populationbased study is needed, with adequate estimation procedures and considering the confounding factors related to the main measurement. The Brazilian population presents optimal conditions for this work, mainly due to the high admixture that occurred in the region since the end of the 18th century, assembling different ancestralities in the same country. ${ }^{14,15}$

This study presents the results of the largest crosssectional population-based study to date on the determinants of skin moisture. This was conducted in a Brazilian sample using a noninvasive method. Here, we describe the associations of this measurement with epidemiological, environmental, and cosmetic variables.

\section{Materials and methods}

\section{Study population and sample design}

All the subjects of this study were participants of the Baependi Heart Study, a genetic epidemiological study of cardiovascular disease risk factors with a longitudinal design in the Brazilian population. The main sampling was designed in a familial scheme in five primary steps consisting of 1) sampling design and selection of census districts, 2) sampling familial structure enrollment, 3) main data recording and physiological measurement, 4) initial analysis, and 5) follow-up. ${ }^{16}$ Baseline enrollment occurred between December 2005 and January 2006 by selecting 1,857 individuals from 95 families in the municipality of Baependi, a city in the state of Minas Gerais in the southeast of Brazil. The population has typical characteristics of a small-sized Brazilian city, with urban and rural regions, and a wide range of age-groups. The study covers $\sim 10 \%$ of the total adult population of the city.

Probands were randomly selected from the community at large in eleven census districts. Once the probands were enrolled, all their first-degree, second-degree, and third-degree relatives as well as those of their spouses living in the surrounding cities and who were at least 18 years old were invited to participate. To elect the participants, the study was advertised through provincial, religious, and municipal authorities, in local radio, television and newspapers, through physicians and also by phone calls. A clinic was established in an easily accessible sector for physical examination. ${ }^{17}$

Main pieces of information, such as family relationships, sociodemographic characteristics, medical history, physiological measurements, and other epidemiological data (smoking and alcohol abuse), were obtained through a closed questionnaire based on the instrument recommended for the WHO MONICA project ${ }^{18}$ and filled by trained research assistants. For this study, an additional questionnaire was applied concerning the presence of environmental exposure to sunlight, hormone replacement therapy, as well as cosmetic use and its frequency. In addition, questions based on self-perception concerning several characteristics of the skin, such as the texture, aging signs, and perceived hydration of the skin, were also performed. From 1,339 subjects who were subjected to this additional protocol simultaneously with SC moisture measurement, 1,176 individuals were identified in one of the pedigree lineages organized until now on the main research sample.

The study protocol was approved by the ethics committee of the Hospital das Clínicas, University of São Paulo Medical School, São Paulo, Brazil (project \#297/12), and all subjects provided informed written consent before participating in the study. The list of variables collected in this study is found in the Supplementary materials section. The present work followed the Strengthening the Reporting of Observational Studies in Epidemiology (STROBE) statement. ${ }^{19}$ All ethical proofs are available upon request.

\section{Corneometer measurement}

The biophysical measurement was performed with a calibrated Corneometer CM820 probe at three different sites: anterior forearm, posterior hand, and submalar region, previously trimmed. Ten technical replicates were performed for each site. Temperature and relative humidity of the air in the application room were previously stabilized and were also recorded. All the participants were instructed not to use any kind of cosmetic or topical drug in the last 24 hours of the measurement in order to verify the extended effect of these products after their use was stopped. All data collection was made between March 2013 and August 2014.

\section{Statistical analysis}

Statistical procedures were used to test and quantify the association between objective measures of the SC moisture 
(obtained by the Corneometer) and the environmental and epidemiological factors as well as the collected self-perception variables of the skin. An initial data consistency check was performed (illegal values checking, invalid answer deletion, cross-checking, and missing data deletion) followed by a descriptive analysis and a confounding analysis. The descriptive analysis aimed to investigate data distribution and possible methodologies for the subsequent statistical modeling. Confounding analysis was intended to verify any possible influence of room temperature and relative humidity in SC measurements for subsequent consideration in the analysis, since there are occasional random variations in room conditions with time.

After preliminary analysis, statistical models were proposed to study the risk and protecting factors for the skin layer moisture. Linear mixed models were used with a kinship matrix for the covariance structure due to parental correlation between subjects, due to the familial sampling scheme, which required an explicit definition of the response covariance behavior. ${ }^{20,21}$ All computations were performed in the R statistical environment (R Foundation for Statistical Computing, Vienna, Austria), ${ }^{22}$ implemented with the lmekin function in the coxme library. ${ }^{23}$ Parallel computing procedures were applied in order to optimize the computation time. The R scripts are available upon request.

Initially, each exposure as well as the epidemiological and perception variables was fitted with age, sex, and confounding covariates (temperature and air humidity) to explain the SC moisture levels of the sample. Two different models were proposed in order to measure both regional and overall effects of covariates in SC moisture: one regression procedure for each body region and a general model with all observations, considering the body site as a random effect due to its different properties is described in the literature. $^{24}$

Final additive and interaction models were constructed considering the main significant variables in previous modeling, intending to verify the effects of covariates in the presence of other significant effects. Ordinal categorical variables were treated as numerical scales when possible.

\section{Results}

Descriptive measures for main variables of the sample are shown in Table 1. Respondents were in the age range of 18-89 years, with an average of 47 years. Eight hundred and forty-seven $(63.25 \%)$ participants were women, and $492(36.74 \%)$ participants were men. Of the 1,339 individuals, $10.8 \%$ were self-attested as smokers, $42 \%$ confirmed regular exposure to sunlight, and $21 \%$ declared
Table I Main descriptive table

\begin{tabular}{|c|c|c|c|}
\hline Variables & Women (n) & Men (n) & All, N (\%) \\
\hline \multicolumn{4}{|l|}{ Age (years) } \\
\hline Mean & 46.773 & 48.539 & 47.422 \\
\hline Median & 48 & 49 & 48 \\
\hline SD & 15.594 & $|7.25|$ & 16.238 \\
\hline \multicolumn{4}{|l|}{$\mathrm{BMI}\left(\mathrm{kg} / \mathrm{m}^{2}\right)$} \\
\hline Mean & 26.106 & 25.826 & 25.926 \\
\hline Median & 25.195 & 24.988 & 25.076 \\
\hline SD & 5.388 & 5.024 & 5.157 \\
\hline \multicolumn{4}{|c|}{ Ethnicity (self-reported) } \\
\hline White & 555 & 338 & $893(66.7 \%)$ \\
\hline Black & 40 & 17 & $57(4.3 \%)$ \\
\hline Mixed & 140 & 81 & $221(16.5 \%)$ \\
\hline \multicolumn{4}{|l|}{ Smoking } \\
\hline No & 559 & 227 & $786(58.7 \%)$ \\
\hline Former smoker & 204 & 188 & $392(29.3 \%)$ \\
\hline Social smoker & 9 & 8 & $17(1.3 \%)$ \\
\hline Yes & 75 & 69 & $144(10.8 \%)$ \\
\hline \multicolumn{4}{|l|}{ Smoking history } \\
\hline Never & 558 & 227 & 785 (58.6\%) \\
\hline Until 5 years & 81 & 67 & $148(11.1 \%)$ \\
\hline $6-10$ years & 43 & 34 & 77 (5.8\%) \\
\hline $11-15$ years & 26 & 28 & $54(4 \%)$ \\
\hline$>15$ years & 138 & 136 & $274(20.5 \%)$ \\
\hline \multicolumn{4}{|c|}{ Alcohol abuse score (0: abstinent and 6: heavy drinking) } \\
\hline Mean & 1.79 & 2.113 & 1.998 \\
\hline Median & 0 & 0 & 0 \\
\hline SD & 4.093 & 5.197 & 4.832 \\
\hline \multicolumn{4}{|l|}{ Sun exposure } \\
\hline Always & 532 & 186 & $718(53.6 \%)$ \\
\hline Sometimes & 46 & 17 & $63(4.7 \%)$ \\
\hline Never & 269 & 289 & $558(41.7 \%)$ \\
\hline \multicolumn{4}{|l|}{ Sunscreen use } \\
\hline Daily & 241 & 33 & $274(20.5 \%)$ \\
\hline Sometimes & 184 & 53 & $237(17.7 \%)$ \\
\hline Occasionally & 76 & 82 & $158(11.8 \%)$ \\
\hline Do not use & 346 & 324 & $670(50 \%)$ \\
\hline \multicolumn{4}{|c|}{ Hormone replacement therapy } \\
\hline No & 753 & 0 & $753(56.5 \%)$ \\
\hline Not currently & 78 & 0 & $78(5.8 \%)$ \\
\hline Yes & 14 & 0 & $14(1 \%)$ \\
\hline Antiaging treatment & 106 & 6 & $167(2.7 \%)$ \\
\hline Total, N (\%) & 847 (63.256\%) & $492(36.744 \%)$ & $1,339(100 \%)$ \\
\hline
\end{tabular}

Abbreviations: SD, standard deviation; BMI, body mass index.

using sunscreen products daily. For self-reported race/color, $893(66.7 \%)$ self-declared as white, 57 self-declared as black (4.3\%), and 221 self-declared as mixed (16.5\%). Detailed descriptive tables, missing rate, and other measures are listed in Tables $\mathrm{S} 1-\mathrm{S} 3$.

For the self-perception variables, it is possible to note that $42 \%$ of the subjects declared their own skin appearance as "regular", while $26 \%$ of the subjects expressed the perception of good skin appearance. When asked regarding the self-perception of the skin moisture, $28 \%$ of the participants affirmed not having a hydrated skin. 
Corneometer observations indicated a symmetric distribution for both genres and body sites. This fact supports a normally distributed assumption modeling for the presented data (Figure S1). Also, the Pearson correlation coefficient was computed, aiming to check possible confounding effects of room temperature and air humidity in the SC measurement. The procedure provided small correlation values but gave statistical evidence for an association between the Corneometer values and temperature $(\mathrm{Rho}=0.082 ; P=0.000015)$ and humidity (Rho $=0.177 ; P<0.00001$ ). These effects were also added to the modeling in order to check their influence in the final analysis (Figure S2).

\section{Initial modeling}

For the proposed initial additive modeling (SC outcome explained by each response plus sex, age, and confounding variables), Figure 1 describes main epidemiological and exposition covariates related to the SC moisture. From the model, it is possible to note that men presented smaller values of skin moisture than women (the reference level). High sun exposure leads to a higher loss of skin moisture for all investigated sites of the body. Age affects the SC moisture, mainly at the sites of hand and anterior forearm. In addition, body mass index and weight show a slightly negative relation with the Corneometer values for the anterior forearm. Self-reported black and mixed races present a strong intrinsic protective factor for different body sites compared to selfdeclared white skin color (the reference level).

Also in this approach, the self-perception modeling coefficients are shown in Figure 2. Analysis shows that individuals who reported having dry or very dry skin, in fact, present smaller measured moisture values. The same inference is possible for subjects who declared poor skin moisture. Also, relevant relationships were found between the Corneometer readings and skin softness, texture, and luminosity perception. The less perceived these perceptions are, the less is the actual skin moisture measure.

\section{Final modeling}

For the multiple regression approach, which includes all the covariates that found relevant to the previous analysis (still considering body site as a random effect), male sex, age, high sun exposure, and sunscreen use still presented significant relationship with SC moisture. Yet, room temperature and air humidity showed evidence of an association with the Corneometer measures, indicating a small (and here treated as) confounding effect. Modeling also confirms the direct proportional protective factor of darker tone of self-reported skin color for SC moisture. The log-likelihood ratio tes $\mathrm{t}^{25}$ provided evidence for this approach against basal models. The estimates are listed in Table 2. Additional coefficients and $P$-values are listed in Table S4.

The computation of a final model with several covariates is justified by the need to verify joint effects of each regressor in the presence of others. This modeling can provide some additional measures to the inference of the SC moisture variation in the population. Generalized $R^{2}$ proposed by Nagelkerke ${ }^{26}$ gives an appropriate quantity to measure the proportion of the total variance explained by the model. In the present case, $18.23 \%$ of the SC moisture measurement variation is explained by the previously mentioned factors, not considering self-perception variables. Genotypic variants and metabolic or other environmental variables can be responsible for unexplained variance. A discussion about these findings is given in the next section. Residual analysis was performed to check the distribution assumptions of the proposed models (Figure S3).

\section{Discussion}

\section{Intrinsic factors associated with SC moisture}

Our findings describe men as more prone to dry skin (in 6.9 moisture units) compared to women. Generally, it is well described, and the literature agrees with the hypothesis of distinct skin properties for each sex, ${ }^{27}$ including SC moisture. ${ }^{28}$ Statistical evidence was found for an association between self-declared race and SC moisture; compared to white race/color (the reference level), black and mixed individuals were found to have a "protective gradient" for the layer property (six moisture units for blacks vs two moisture units for mixed race). Previous works reported no relationship or only a small relationship between skin surface hydration and race. ${ }^{29-31}$ However, most previous studies ${ }^{29}$ were conducted in small samples. In addition, the Brazilian population has a high admixture degree ${ }^{32}$ that differs from most of the studies performed with small samples from specific ethnic groups. In the final modeling, even with the effect of solar exposure, the data presented strong evidence for this fact, which tempts us to suggest that this relationship is a product of genetic ancestrality variations modulating SC moisture with reciprocal action on epidermal melanin photoprotective properties.

Concerning the effect of aging on SC moisture properties, Marrakchi and Maibach ${ }^{33}$ have affirmed that previous works 


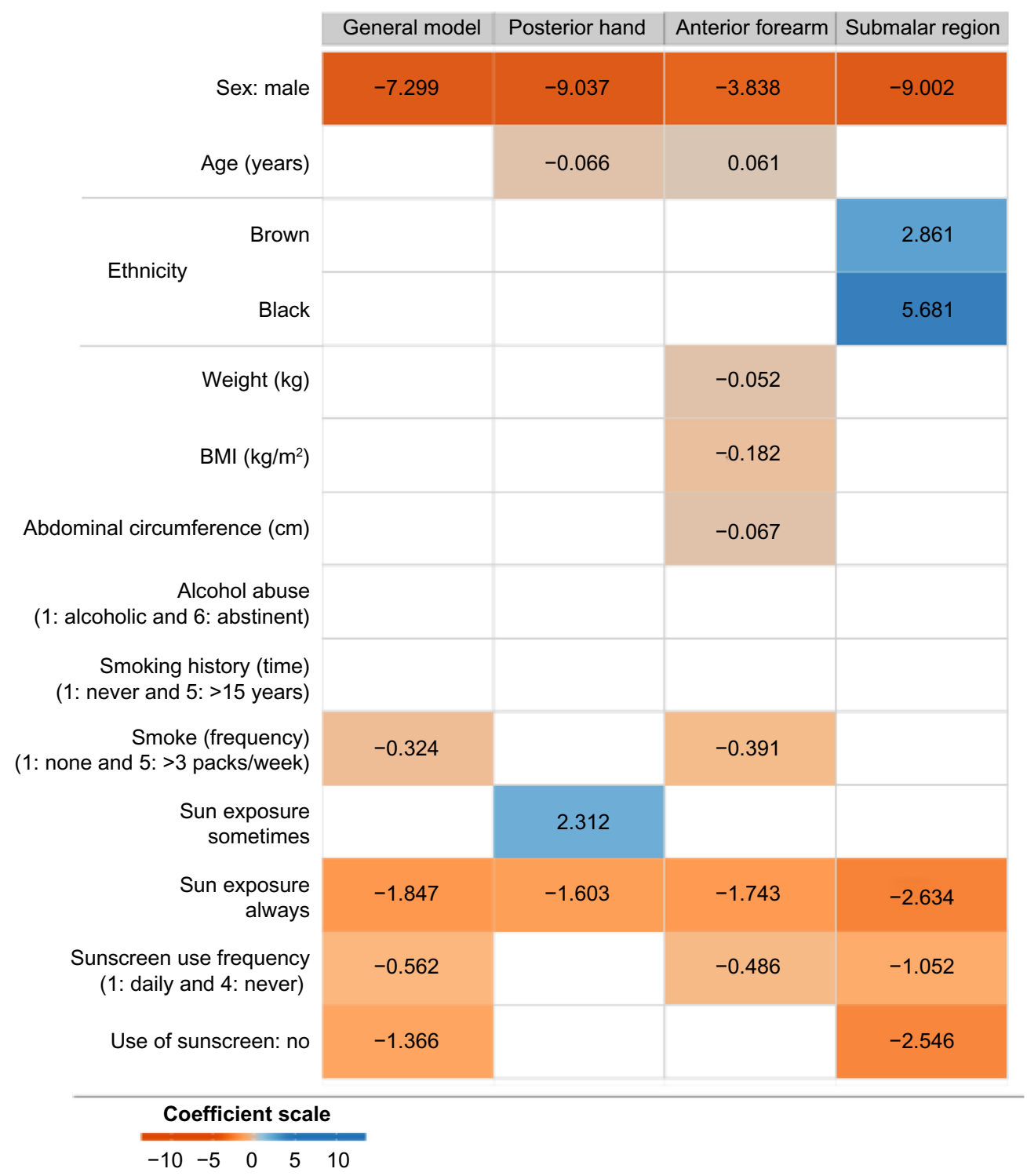

Figure I Diagram displaying effect intensity on stratum corneum moisture of each mainly studied covariate in initial modeling.

Notes: Values in the boxes show estimated coefficients of each model. Negative effects are displayed in red scale, while positive effects are shown in blue tones and values next to zero (nonsignificant) present gray tone. Empty boxes represent no significant relationship (critical $P$-value $>0.025$ ). One can see strong inverse association between the Corneometer measurement and the male sex and high sun exposure. In this model, the reference level for sex is female, and the reference level for sun exposure is never exposed. Alcohol abuse, smoking time, and frequency are taken as numerical scale.

showed conflicting results concerning the effect of aging on skin surface moisture, and suggested studies in homogeneous groups in order to reduce race and sex effects in the results. Tagami $^{34}$ underlined relevant differences in the perioral surface hydration according to age in a group of Chinese women. Darlenski and Fluhr reported an increased skin dryness with age in the photoexposed areas, while Diridollou et al ${ }^{35}$ emphasized this fact for lighter skin tones. In this study, no effect was found for the influence of age on the SC moisture for the submalar region even in the presence of race or sex effects. However, significant effects were found in others sites.
This difference can be explained by the structural variance found in the facial skin according to the region. ${ }^{36}$

\section{Extrinsic factors associated with SC moisture}

Solar ultraviolet (UV) radiation exposure has been described by several authors as harmful for several skin processes and properties. Bonté ${ }^{37}$ related skin dryness with damage due to chronic sun exposure, and Humbert ${ }^{38}$ reported its effects on the skin's youthfulness. In fact, this study shows smaller values of SC moisture for subjects who referred to frequent 


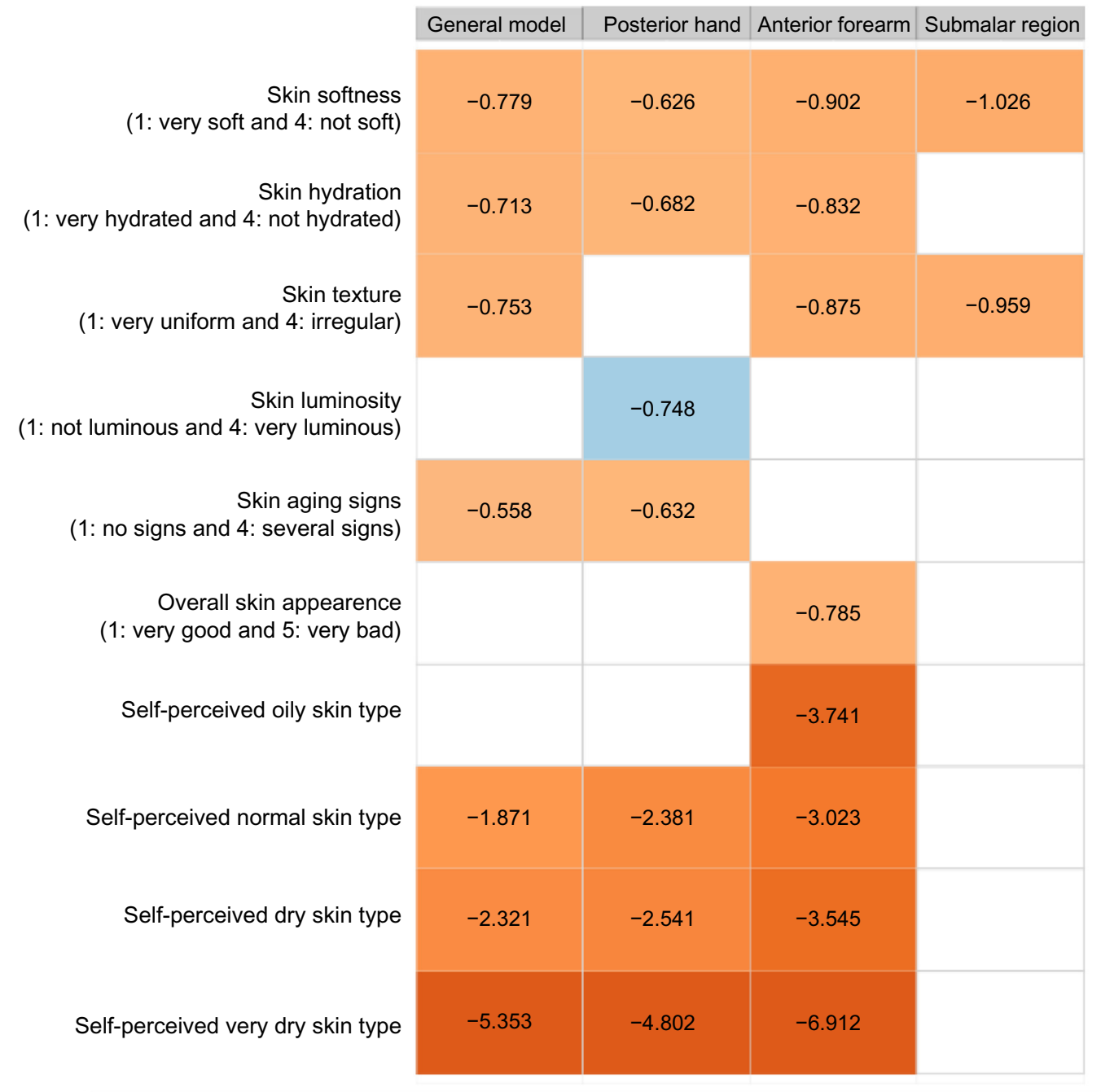

\section{Coefficient scale}

$-10-5 \quad 0 \quad 5 \quad 10$

Figure 2 Diagram displaying effect intensity on stratum corneum moisture of each self-perception question in initial modeling.

Notes: Values in the boxes show the estimated coefficients of each model. Negative effects are displayed in red scale, while positive effects are shown in blue tones and values next to zero (nonsignificant) presents gray tone. Empty boxes represent no significant relationship (critical $P$-value $>0.025$ ). One can see strong association between the Corneometer measurement and the self-perceived dry and very dry skin of the participants. It is also possible to note this relation for perception of skin softness, hydration, texture, and luminosity. In this model, the reference level for self-perceived skin type is mixed skin.

sun exposure, in all the studied body sites. Most studies describe this fact through clinical experiments; we confirm the role of solar exposure based on the epidemiological point of view, leading to high evidence that the aftereffects of excessive solar exposure influence this skin property in the general population.

The literature presents relevant associations between smoking and skin damage or related diseases, ${ }^{39}$ mainly for events centered on the epidermis. Despite the small number of studies investigating changes on SC properties, the authors agree with the hypothesis that smoking leads to several changes in the organ, ${ }^{40}$ including less water content on SC..$^{41,42}$ In the present case, smoking frequency shows evidence for an action in SC moisture for the anterior forearm.

Derraik et al ${ }^{43}$ showed a high association between body weight and skin thickness, and Kim et $\mathrm{al}^{44}$ showed the relation between the thickness and moisture of SC in an animal sample of hairless mice. Our results indicate that body mass index and weight are associated with forearm SC moisture. This finding suggests that moisture of the skin is a product not only of the molecular processes of the layer but also of the structural organization of the stratum, where the moisture level is proportional to the thickness, with changes occurring due to increased weight in specific body sites. In fact, Guida et $\mathrm{al}^{45}$ showed higher transepidermal water loss in obese 
Table 2 Coefficient estimates and associated $P$-values for covariates for final proposed model

\begin{tabular}{|c|c|c|c|}
\hline Covariate/level & Coefficient & Standard error & $P$-value \\
\hline Intercept & 5.807821 & 4.185529 & 0.17 \\
\hline Temperature & 0.867252 & 0.129443 & $<|\times| 10 E-10$ \\
\hline Air humidity & 0.204178 & 0.019874 & $<1 \times 10 E-10$ \\
\hline \multicolumn{4}{|l|}{ Sex } \\
\hline Male & -5.94138 & 0.427233 & $<1 \times 10 E-10$ \\
\hline Age & 0.032517 & 0.012337 & 0.0084 \\
\hline BMI & -0.07749 & $0.03864 I$ & 0.045 \\
\hline \multicolumn{4}{|l|}{ Ethnicity } \\
\hline Brown & 0.976346 & 0.507066 & 0.054 \\
\hline Black & 2.387815 & 1.025978 & 0.02 \\
\hline \multicolumn{4}{|l|}{ Sun exposure } \\
\hline Eventually & I.145759 & 0.878445 & 0.19 \\
\hline Always & -2.05304 & 0.393892 & $<|\times| 10 E-10$ \\
\hline Sunscreen use & -0.52107 & 0.163704 & 0.0015 \\
\hline
\end{tabular}

Notes: $P$-values in bold indicate significance at 0.05 . Reference level for sex is female, reference level for smoking is not smoking, reference level for sun exposure is never exposed, and reference level for self-perceived skin type is mixed skin. Abbreviation: BMI, body mass index.

individuals, linking this fact with metabolic changes in this group. Further investigations covering the link between metabolism variations and SC moisture and thickness properties are warranted.

After 24 hours without using any type of cosmetics, weak evidence was found for extended effects of the products on the SC moisture for this sample. This implies that most moisturizers or other products present only short-term effects on skin hydration properties. The dynamics of the layer poses difficulties for the development of protective agents for the skin. Nevertheless, sunscreen use presented a high association with the $\mathrm{SC}$ moisture levels as a protective factor against sun exposure, according to its frequency of use, showing lower moisture levels in individuals who used sunscreen irregularly. It is also important to note that the coefficients found in modeling present higher values of sun exposure effect than the coefficient for sunscreen use, indicating that, on average, even subjects who use sunscreen regularly present a significant influence of sun exposure on skin moisture.

Only a few studies relate self-perceived dryness with skin surface hydration. ${ }^{46,47}$ The proposed models present very significant coefficients for the relation between poor skin moisture self-perception and small values for Corneometer measurements. This relation is still significant when individuals respond having dry or very dry skin or refer lower levels of softness, texture, and luminosity of the skin. These results show that the condition of the SC moisture, different from other skin properties, is easily perceived by the individual.
Evidence for the influence of air humidity and temperature with the Corneometer measures confirms the sensitivity of the capacitance-based equipment by external factors, which needs to be considered in all experimental designs in this area, as stated by previous authors. ${ }^{48,49}$

Based on the additional results, $18.23 \%$ of the total variation of the SC moisture could be explained by the variables presented in this study. This implies that several other intrinsic and extrinsic effects can also modify skin surface moisture, including genetic variants, metabolic covariates, physiological covariates, and other environmental covariates, interacting and modifying each other, a fact that explains the complexity to improve the technology based on the layer, such as cosmetic formulation and topical drug delivery systems. ${ }^{50}$

The discovery that self-perception of skin dryness is related to real skin condition can be applied in several ways from the development of products based partially on a self-reported skin history to automated systems based on a self-reported score of the skin moisture for the prediction of diseases linked to the layer.

\section{Conclusion}

Special attention is needed for the fact that solar UV exposure is a potential public health issue, concerning the cumulative sun damage caused in skin and the excessive unprotected sun exposure in several segments of the population. Since SC plays an active role in protecting the body from photodamage, quantified by Young and Sheehan ${ }^{51}$ as on the order of $66 \%$, the risk of diseases related to changes in the organ, such as xerosis $^{52}$ and eczema, ${ }^{53}$ dramatically increases associated with individual habits and traits described in this study, such as smoking and obesity.

Based on the present results, we propose that experimental design in this area must be performed in different age- and sex groups and also in different skin tones and layer thicknesses to cover different responses of the skin due to structural changes in SC sites. We also propose that chemical formulation of products must present properties of stability toward exogenous processes (such as smoking and pollution), high photostability, and a broad spectrum action in the mentioned groups.

Based on a large sample from a highly admixed population, this study corroborated the literature concerning the effects of sex, age, sun exposure, sunscreen use, and other epidemiological factors on SC moisture and discussed about the effects of age and other covariates on this property. This study also established the concordance between objective skin 
moisture measures and the self-perception of skin dryness. The presented work showed that the variation of measured moisture is due to several factors, including the environmental temperature and relative humidity.

\section{Disclosure}

The authors report no conflicts of interest in this work.

\section{References}

1. Candi E, Schmidt R, Melino G. The cornified envelope: a model of cell death in the skin. Nat Rev Mol Cell Biol. 2005;6(4):328-340.

2. Robinson M, Visscher M, Laruffa A, Wickett R. Natural moisturizing factors (NMF) in the stratum corneum (SC). I. Effects of lipid extraction and soaking. J Cosmet Sci. 2010;61(1):13-22.

3. Imokawa G, Kuno H, Kawai M. Stratum corneum lipids serve as a bound-water modulator. J Invest Dermatol. 1991;96(6):845-851.

4. Marks R. The stratum corneum barrier: the final frontier. $J$ Nutr. 2004;134(8 suppl):2017S-2021S.

5. Lampe MA, Burlingame AL, Whitney J, et al. Human stratum corneum lipids: characterization and regional variations. J Lipid Res. 1983;24(2):120-130.

6. Rogers J, Harding C, Mayo A, Banks J, Rawlings A. Stratum corneum lipids: the effect of ageing and the seasons. Arch Dermatol Res. 1996;288(12):765-770.

7. Ghadially R, Reed JT, Elias PM. Stratum corneum structure and function correlates with phenotype in psoriasis. $J$ Invest Dermatol. 1996;107(4):558-564.

8. Yamamoto A, Serizawa S, Ito M, Sato Y. Stratum corneum lipid abnormalities in atopic dermatitis. Arch Dermatol Res. 1991;283(4): 219-223.

9. Sybert VP. Genetic Skin Disorders. New York, NY: Oxford University Press; 2010.

10. Darlenski R, Sassning S, Tsankov N, Fluhr JW. Non-invasive in vivo methods for investigation of the skin barrier physical properties. Eur J Pharm Biopharm. 2009;72(2):295-303.

11. Fluhr J. Bioengineering of the Skin Water and Stratum Corneum. Boca Raton: CRC Press; 2005.

12. Li F, Conroy E, Visscher M, Wickett RR. The ability of electrical measurements to predict skin moisturization. I. Effects of $\mathrm{NaCl}$ and glycerin on short-term measurements. J Cosmet Sci. 2001;52(1):13-22.

13. Lodén M, Maibach HI, editors. Treatment of Dry Skin Syndrome: The Art and Science of Moisturizers. Berlin/New York, NY: Springer; 2012.

14. Telles EE [webpage on the Internet]. Race in another America: The Significance of Skin Color in Brazil; 2006. Available from: http://search. ebscohost.com/login.aspx?direct=true \&scope $=$ site $\& \mathrm{db}=\mathrm{nlebk} \& \mathrm{db}=\mathrm{nla}$ bk\&AN=718031. Accessed January 19, 2015.

15. Parra FC, Amado RC, Lambertucci JR, Rocha J, Antunes CM, Pena SDJ. Color and genomic ancestry in Brazilians. Proc Natl Acad Sci U S A. 2003;100(1):177-182.

16. Gauderman WJ, Macgregor S, Briollais L, et al. Longitudinal data analysis in pedigree studies. Genet Epidemiol. 2003;25(S1):S18-S28.

17. Giolo SR, Soler JMP, Greenway SC, et al. Brazilian urban population genetic structure reveals a high degree of admixture. Eur J Hum Genet. 2012;20(1):111-116.

18. World Health Organization. In: Tunstall-Pedoe H, editor. MONICA, Monograph, and Multimedia Sourcebook: World's Largest Study of Heart Disease, Stroke, Risk Factors, and Population Trends 1979-2002. Geneva: World Health Organization; 2003.

19. Von Elm E, Altman DG, Egger M, et al; STROBE Initiative. The strengthening the reporting of observational studies in epidemiology (STROBE) statement: guidelines for reporting observational studies. J Clin Epidemiol. 2008;61(4):344-349.

20. Lange K. Mathematical and Statistical Methods for Genetic Analysis. 2nd ed. New York, NY: Springer; 2002.
21. Therneau T. On Mixed-Effect Cox Models, Sparse Matrices, and Modeling Data from Large Pedigrees. Rochester, MN: CiteSeerX; 2003.

22. Ihaka R, Gentleman R. R: a language for data analysis and graphics. J Comput Graph Stat. 1996;5(3):299.

23. Therneau T. The Lmekin Function. Rochester, MN: Mayo Clinic; 2012.

24. Darlenski R, Fluhr JW. Influence of skin type, race, sex, and anatomic location on epidermal barrier function. Clin Dermatol. 2012;30(3):269-273.

25. Fox J. Applied Regression Analysis, Linear Models, and Related Methods. Thousand Oaks, CA: Sage Publications; 1997:597.

26. Nagelkerke NJD. A note on a general definition of the coefficient of determination. Biometrika. 1991;78(3):691.

27. Tagami H. Stratum Corneum Cell Layers. In: Farage MA, Miller KW, Maibach HI, editors. Textbook of Aging Skin. Berlin, Heidelberg: Springer Berlin Heidelberg; 2010:377-383.

28. Dao H, Kazin RA. Gender differences in skin: a review of the literature. Gend Med. 2007;4(4):308-328.

29. Wesley NO, Maibach HI. Racial (ethnic) differences in skin properties: the objective data. Am J Clin Dermatol. 2003;4(12):843-860.

30. Firooz A, Sadr B, Babakoohi S, et al. Variation of biophysical parameters of the skin with age, gender, and body region. Sci World J. 2012;2012:1-5.

31. Fotoh C, Elkhyat A, Mac S, Sainthillier JM, Humbert P. Cutaneous differences between Black, African or Caribbean mixed-race and Caucasian women: biometrological approach of the hydrolipidic film. Skin Res Technol. 2008;14(3):327-335.

32. Queiroz EM, Santos AM, Castro IM, et al. Genetic composition of a Brazilian population: the footprint of the Gold Cycle. Genet Mol Res. 2013;12(4):5124-5133.

33. Marrakchi S, Maibach HI. Skin reactivity of the human face: functional map and age related differences. In: Farage MA, Miller KW, Maibach HI, editors. Textbook of Aging Skin. Berlin: Springer; 2010: 173-182.

34. Tagami H. Location-related differences in structure and function of the stratum corneum with special emphasis on those of the facial skin. Int J Cosmet Sci. 2008;30(6):413-434.

35. Diridollou S, de Rigal J, Querleux B, Leroy F, Holloway Barbosa V. Comparative study of the hydration of the stratum corneum between four ethnic groups: influence of age. Int J Dermatol. 2007;46(s1):11-14.

36. Arda $\mathrm{O}$, Göksügür N, Tüzün Y. Basic histological structure and functions of facial skin. Clin Dermatol. 2014;32(1):3-13.

37. Bonté F. Skin moisturization mechanisms: new data. Ann Pharm Fr. 2011;69(3):135-141.

38. Humbert P. Assessment of cumulative exposure to UVA through study of asymmetric facial skin damage. Clin Interv Aging. 2010;5:277.

39. Thomsen SF, Sørensen LT. Smoking and skin disease. Skin Therapy Lett. 2010;15(6):4-7.

40. Farage MA, Miller KW, Elsner P, Maibach HI. Intrinsic and extrinsic factors in skin ageing: a review. Int J Cosmet Sci. 2008;30(2): $87-95$.

41. Boyd AS, Stasko T, King LE, Cameron GS, Pearse AD, Gaskell SA. Cigarette smoking-associated elastotic changes in the skin. J Am Acad Dermatol. 1999;41(1):23-26.

42. Wolf R, Tur E, Wolf D, Landau M. The effect of smoking on skin moisture and on surface lipids. Int J Cosmet Sci. 1992;14(2):83-88.

43. Derraik JGB, Rademaker M, Cutfield WS, et al. Effects of age, gender, BMI, and anatomical site on skin thickness in children and adults with diabetes. PLoS One. 2014;9(1):e86637.

44. Kim KW, Choi HY, Sim MH, et al. Compensation on impedance of the stratum corneum. J Electr Eng Technol. 2008;3(3):444-449.

45. Guida B, Nino M, Perrino N, et al. The impact of obesity on skin disease and epidermal permeability barrier status. J Eur Acad Dermatol Venereol. 2010;24(2):191-195.

46. Hawkins SS, Subramanyan K, Liu D, Bryk M. Cleansing, moisturizing, and sun-protection regimens for normal skin, self-perceived sensitive skin, and dermatologist-assessed sensitive skin. Dermatol Ther. 2004;17(suppl 1):63-68. 
47. Willis CM, Shaw S, De Lacharrière O, et al. Sensitive skin: an epidemiological study. Br J Dermatol. 2001;145(2):258-263.

48. Cheng Y, Dong Y, Dong M, et al. Protection effect of cosmetics on human skin under simulated rigorous environment. Skin Res Technol. 2007;14(1):45-52.

49. Qiu H, Long X, Ye JC, et al. Influence of season on some skin properties: winter vs. summer, as experienced by 354 Shanghaiese women of various ages: influence of season on some skin properties. Int J Cosmet Sci. 2011;33(4):377-383.

50. Leite-Silva VR, de Almeida MM, Fradin A, Grice JE, Roberts MS. Delivery of drugs applied topically to the skin. Expert Rev Dermatol. 2012;7(4):383-397.
51. Young AR, Sheehan JM [webpage on the Internet]. Chapter 18 UV-Induced Pigmentation in Human Skin. Comprehensive Series in Photosciences. Elsevier; 2001:357-375 [cited August 3, 2015]. Available from: http://linkinghub.elsevier.com/retrieve/pii/S1568461X01800533. Accessed January 14, 2016.

52. Horii I, Nakayama Y, Obata M, Tagami H. Stratum corneum hydration and amino acid content in xerotic skin. $\mathrm{Br} J$ Dermatol. 1989;121(5):587-592.

53. Jungersted JM, Scheer H, Mempel M, et al. Stratum corneum lipids, skin barrier function and filaggrin mutations in patients with atopic eczema: filaggrin mutations, skin barrier and lipids. Allergy. 2010;65(7):911-918.

\section{Publish your work in this journal}

Clinical, Cosmetic and Investigational Dermatology is an international, peer-reviewed, open access, online journal that focuses on the latest clinical and experimental research in all aspects of skin disease and cosmetic interventions. All areas of dermatology will be covered; contributions will be welcomed from all clinicians and basic science researchers globally. This journal is indexed on CAS. The manuscript management system is completely online and includes a very quick and fair peer-review system, which is all easy to use. Visit http://www.dovepress.com/testimonials.php to read real quotes from published authors.

Submit your manuscript here: http://www.dovepress.com/clinical-cosmetic-and-investigational-dermatology-journal 